\title{
ARTICLE
}

Lymphoma

\section{The AP-1-BATF and -BATF3 module is essential for growth, survival and TH17/ILC3 skewing of anaplastic large cell lymphoma}

\author{
Nikolai Schleussner ${ }^{1,2}$ - Olaf Merkel ${ }^{3,4}$ - Mariantonia Costanza $\mathbb{D}^{1,2,4}$. Huan-Chang Liang ${ }^{3,4} \cdot$ Franziska Hummel $^{1,2}$. \\ Chiara Romagnani, ${ }^{5,6}$ - Pawel Durek ${ }^{5}$ - loannis Anagnostopoulos ${ }^{7}$ - Michael Hummel ${ }^{7,8} \cdot$ Korinna Jöhrens $^{7}$. \\ Antonia Niedobitek ${ }^{1,2}$ - Patrick R. Griffin ${ }^{9}$ - Roberto Piva ${ }^{10}$ - Henrike L. Sczakiel ${ }^{1,2}$ - Wilhelm Woessmann ${ }^{4,11}$. \\ Christine Damm-Welk ${ }^{4,11} \cdot$ Christian Hinze $^{1,12} \cdot$ Dagmar Stoiber $^{13,14} \cdot$ Bernd Gillissen $^{2} \cdot$ Suzanne D. Turner ${ }^{4,15}$. \\ Eva Kaergel $^{1} \cdot$ Linda von Hoff $^{1} \cdot$ Michael Grau $^{16,17} \cdot$ Georg Lenz $^{16,17} \cdot$ Bernd Dörken $^{1,2,8} \cdot$ Claus Scheidereit $^{1}$. \\ Lukas Kenner ${ }^{3,4,14,18,19} \cdot$ Martin Janz ${ }^{1,2,20} \cdot$ Stephan Mathas ${ }^{1,2,4,8,20}$
}

Received: 8 March 2017 / Revised: 20 December 2017 / Accepted: 8 January 2018 / Published online: 28 March 2018

(c) The Author(s) 2018. This article is published with open access

\begin{abstract}

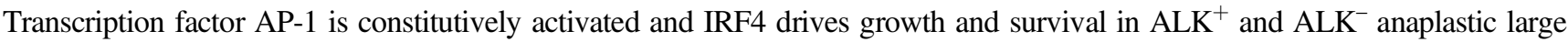
cell lymphoma (ALCL). Here we demonstrate high-level BATF and BATF3 expression in ALCL. Both BATFs bind classical AP-1 motifs and interact with in ALCL deregulated AP-1 factors. Together with IRF4, they co-occupy AP-1-IRF composite elements, differentiating ALCL from non-ALCL. Gene-specific inactivation of BATFs, or global AP-1 inhibition results in ALCL growth retardation and/or cell death in vitro and in vivo. Furthermore, the AP-1-BATF module establishes TH17/group 3 innate lymphoid cells (ILC3)-associated gene expression in ALCL cells, including marker genes such as AHR, IL17F, IL22, IL26, IL23R and ROR $\gamma$. Elevated IL-17A and IL-17F levels were detected in a subset of children and adolescents with ALK ${ }^{+}$ ALCL. Furthermore, a comprehensive analysis of primary lymphoma data confirms TH17-, and in particular ILC3-skewing in ALCL compared with PTCL. Finally, pharmacological inhibition of RORC as single treatment leads to cell death in ALCL cell lines and, in combination with the ALK inhibitor crizotinib, enforces death induction in ALK ${ }^{+}$ALCL. Our data highlight the crucial role of AP-1/BATFs in ALCL and lead to the concept that some ALCL might originate from ILC3.
\end{abstract}

\section{Introduction}

Transcription factors (TFs) are crucial determinants of hematopoietic malignancies [1,2]. One example of lymphoid neoplasms with distinct dysregulated TF activities is anaplastic large cell lymphoma (ALCL) [3, 4]. The WHO classification distinguishes ALK-positive $\left(\mathrm{ALK}^{+}\right) \mathrm{ALCL}$, which is characterized by the $N P M-A L K$ fusion, and ALK-

These authors contributed equally: Nikolai Schleussner, Olaf Merkel.

Electronic supplementary material The online version of this article (https://doi.org/10.1038/s41375-018-0045-9) contains supplementary material, which is available to authorized users.

\footnotetext{
Lukas Kenner

lukas.kenner@meduniwien.ac.at

Stephan Mathas

stephan.mathas@charite.de
}

Extended author information available on the last page of the article negative (ALK ${ }^{-}$) ALCL lacking $A L K$ translocations [5]. Both belong to peripheral T-cell lymphomas (PTCLs). Whereas ALK is considered as causative of $\mathrm{ALK}^{+} \mathrm{ALCL}$ [6], the pathogenesis of $\mathrm{ALK}^{-}$ALCL is less clarified [7, 8].

Albeit both ALCL entities show differences in genomic alterations or gene and microRNA expression [9-11], phenotypically they are highly similar and share biological and molecular key aspects [12-14]. In particular, their deregulated TF programs overlap. They share STAT3 and NOTCH1 activation and high-level interferon regulatory factor 4 (IRF4) and MYC (v-myc myelocytomatosis viral oncogene homo$\log$, c-MYC) expression and activity [7, 13, 15-17]. Moreover, we revealed a unique AP-1 activation in ALCL [14, 18, 19]. Several lines of evidence point toward a crucial role of AP-1 in ALCL: NPM-ALK induces JUNB and JUN [20-22], genomic gains of $J U N B$ and FRA2 loci are found in ALCL $[23,14]$, inhibition of AP-1 in $\mathrm{ALK}^{+}$ALCL results in growth arrest and cell death [18, 21, 24], and JUNB and JUN deletion in mouse models impairs NPM-ALK-driven lymphomagenesis [25]. Finally, expression of the AP-1 interacting TF 
BATF3 distinguishes ALCL from other PTCL [26] and is involved in growth control and survival of ALCL [27].

BATFs, comprising BATF, BATF2 and BATF3, are basic leucine zipper TFs, which modulate transcription primarily by interaction with JUN proteins [28]. The lack of a transactivation domain [28], their redundancy [29], and the number of interaction partners make functional characterization of BATFs challenging. Initially thought to inhibit transcription, recent work highlighted positive regulatory functions of BATFs [28-30]. IRF4 and BATF enhance each other's DNA binding [31], and they cooperatively bind to so-called AP-1-IRF composite elements (AICEs) [29, 31, 32]. Moreover, STAT3, IRF4, JUNB and BATF TFs initiate the fate of $\mathrm{T}$ helper 17 (TH17) cells, which subsequently enforces expression of the key TH17 TF RORC2 (murine ROR $\gamma \mathrm{t}$ ) [33, 34]. Regarding this TF network and TH17-associated genes, characteristic features are shared with group 3 innate lymphoid cells (ILC3) [35].

Given the role of BATF TFs in this regulatory network and expression of STAT3, IRF4, JUNB and BATF3 in ALCL, we investigated expression and function of BATFs in ALCL.

\section{Materials and methods}

\section{Cell lines, culture conditions and transfections}

ALCL (Karpas-299 [named K299], SU-DHL-1, DEL, JB6, SUP-M2, all $\mathrm{ALK}^{+}$; Mac-1, Mac-2A, FE-PD, DL40, all $\mathrm{ALK}^{-}$), T-cell leukemia-derived (Jurkat, KE-37, Molt-14, H9) and HEK293 cell lines were cultured as described [14]. Where indicated, $1 \mu \mathrm{g} / \mathrm{ml}$ doxycycline (Dox; Sigma), the ALK inhibitor crizotinib (Selleckchem), the RORC antagonists SR2211, SR1903 (both in-house generated, laboratory PRG) and GSK805 (Calbiochem), or dimethylsulfoxide (DMSO) control was added. For transient transfections and generation of A-Fos-inducible cells, see Supplementary Methods.

\section{DNA constructs}

CMV500-based A-Fos for constitutive expression has been described [36]. For BATF, BATF3, RORC1, RORC2, and pRTS-1-based [37] inducible A-Fos expression constructs and lentiviral sgRNA and BATF and BATF3 constructs, refer to Supplementary Methods.

\section{siRNA-mediated knock-down and CRISPR/Cas9- mediated deletion of BATF and BATF3 in ALCL cell lines, chromatin immunoprecipitation (ChIP)}

Accell small interfering RNAs (siRNAs) were from Dharmacon (Supplementary Table 1) and passively transfected once into K299 and Mac-1 cells using RPMI-1640 and $1 \%$ fetal calf serum. Cells were cultivated at 500-750 nM for each siRNA for $72 \mathrm{~h}$ (3 days). Knock-down efficiency was controlled by western blot (WB) at day 3 . Functional assays were performed in standard medium. For CRISPR/Cas9-mediated deletion of BATF and BATF3, see Supplementary Methods and Supplementary Table 1; for ChIP, see Supplementary Methods and Supplementary Table 2.

\section{Processing and analysis of microarray data; gene set enrichment analysis (GSEA) and principal component (PC) analysis}

For generation of TH17 and ILC3 signatures, microarray data for TH17, ILC3 and TH1 cells were obtained from GEO (GSE78897) [35]. Primary ALCL and PTCL data were obtained from GEO (GSE65823, GSE6338 and GSE19069) [38-40]. For microarray analyses of cell lines, supplementation by ILC3 microarray data, GSEA and PC analyses, refer to Supplementary Methods.

\section{Additional materials and methods}

Detailed methodology is described in the Supplementary Materials and Methods.

\section{Results}

\section{Characterization of BATF DNA binding and physical interactions of BATFs with JUNB in ALCL}

To identify BATF-containing TF complexes in ALCL, we first analyzed AP-1 DNA binding at the classical AP-1 5'TGA[G/C]TCA-3' motif (Supplementary Figure 1A, top) in a panel of $\mathrm{ALK}^{+}$and $\mathrm{ALK}^{-} \mathrm{ALCL}$ and T-cell-derived control (non-ALCL) cell lines already used in our previous studies [13, 18]. We verified ALCL-restricted AP-1 DNA binding activity and high-level JUNB and IRF4 expression (Supplementary Figure 1A) [13, 18]. Supershift analyses revealed DNA binding of the AP-1/FOS members JUNB and FRA2 [14, 18], and in addition strong BATF binding (Fig. 1a, left). In other cellular systems, BATF-JUN drives gene expression together with IRFs from AP-1 IRF composite elements (AICEs) [29, 31, 32]. DNA binding at AICEs was strong in ALCL, in contrast to non-ALCL (Fig. 1a, right). Supershifts demonstrated binding of FRA2 (weaker compared with the classical AP-1 motif), JUNB and, more prominently, BATF, as well as BATF3 and IRF4 (Fig. 1b, left). Immunoprecipitation demonstrated protein-protein interactions between BATF and BATF3 with JUNB specifically in ALCL cell lines (Fig. 1b, right, and Supplementary Figure 1B). 
A
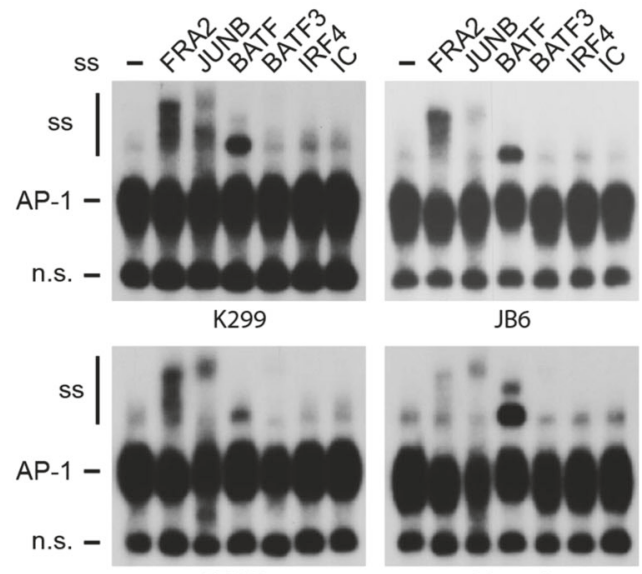

FE-PD
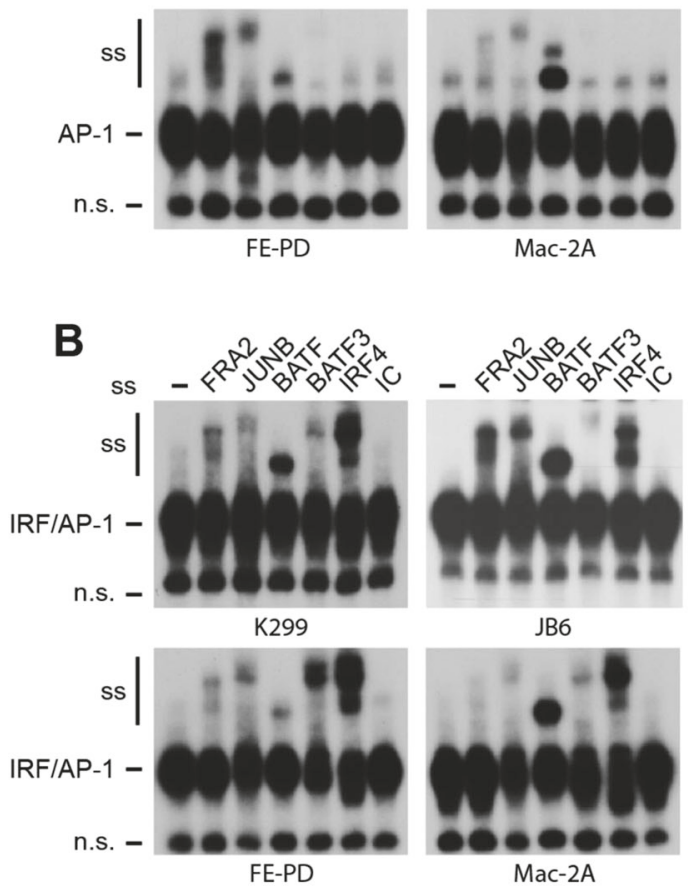

Mac-2A

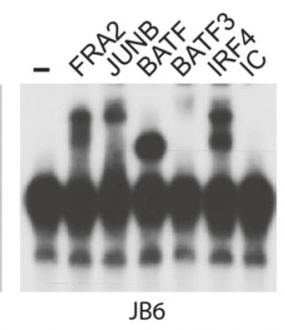

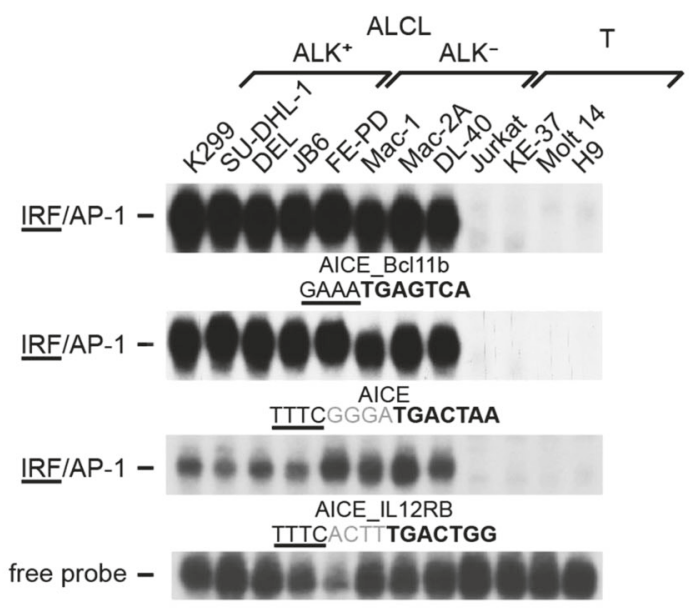
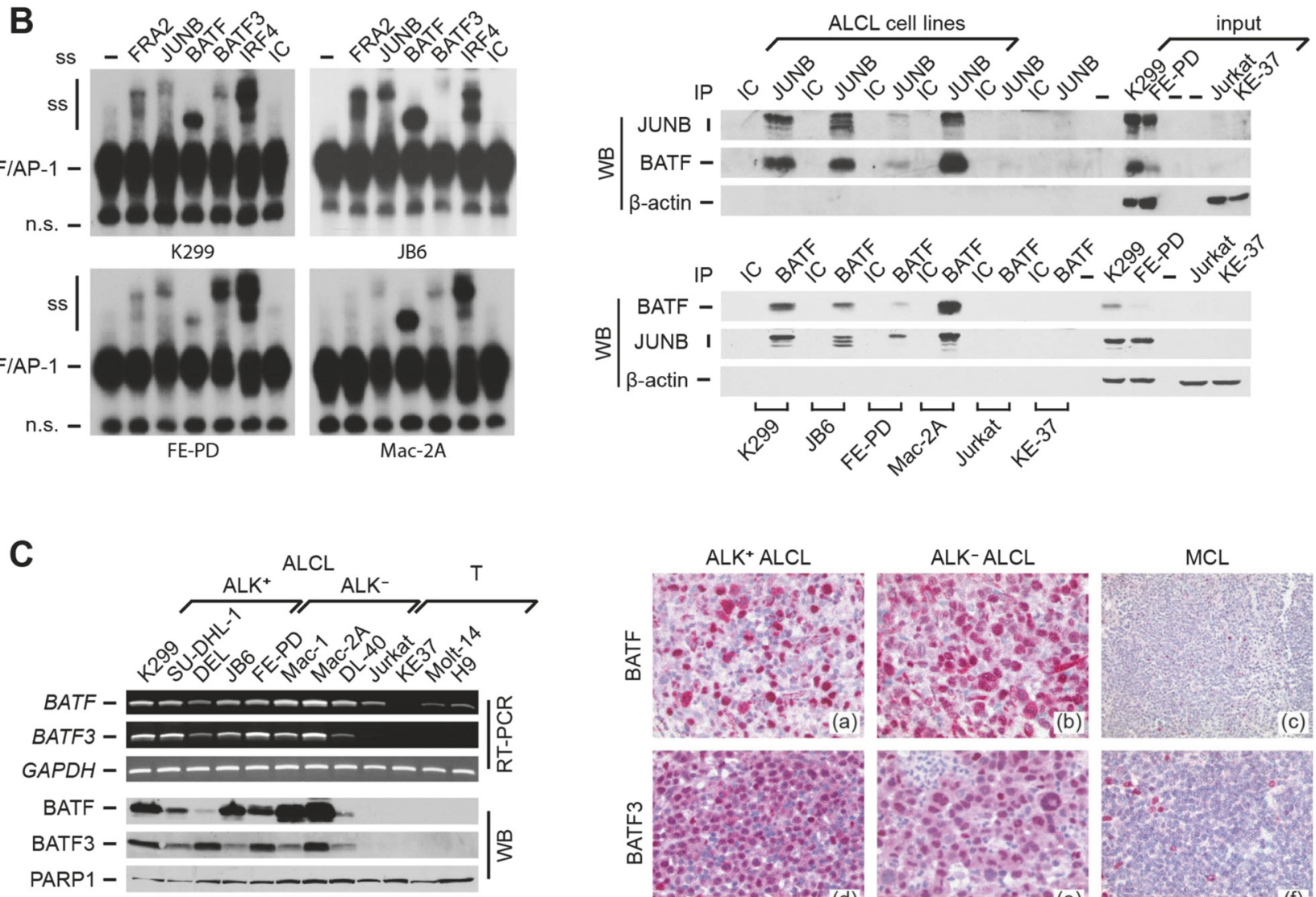

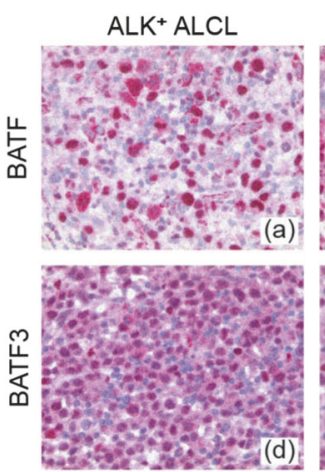

$\mathrm{ALK}^{+} \mathrm{ALCL}$

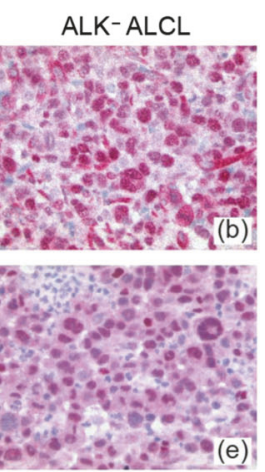

$A L K-A L C L$

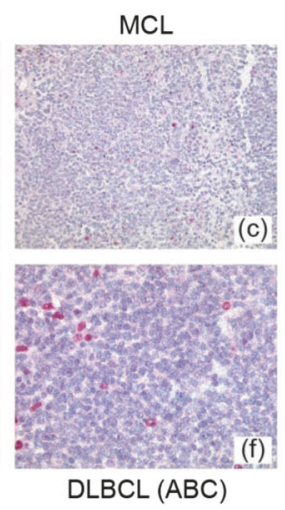

$\operatorname{DLBCL}(A B C)$

Fig. 1 BATF and BATF3 DNA binding, co-immunoprecipitation and expression in ALCL. a Left, EMSA of AP-1 TPA responsive element (TRE) complexes without (-) or with addition of specific antibodies, or isotype control (IC). Positions of AP-1 complexes, supershifts (ss) and a nonspecific band (n.s.) are indicated. Right, EMSA of IRF/AP-1 DNA binding at AICEs (AICE_Bcl11b; AICE; AICE_IL12RB). Underlined, IRF motif; bold, AP-1 motif; gray, intervening bases. The free probe of one representative EMSA is shown. b Left, EMSA of AICE_Bcl11b, performed as in a. Right, JUNB and BATF co-

immunoprecipitations with anti-JUNB (top), anti-BATF (bottom) or isotype controls (IC). (Co-)immunoprecipitated proteins were detected by immunoblotting (WB). $\beta$-Actin and input were controls. c Left, BATF and BATF3 were analyzed at mRNA levels by RT-PCR (top) and at protein level by immunoblotting of nuclear extracts (bottom). GAPDH and PARP1 were controls. Right, BATF and BATF3 IHC of primary lymphomas. Top, BATF IHC of an $\mathrm{ALK}^{+} \mathrm{ALCL}$ a, an $\mathrm{ALK}^{-}$ ALCL $\mathbf{b}$ and a mantle cell lymphoma [MCL; c]. Bottom, BATF3 IHC of an $\mathrm{ALK}^{+} \mathrm{ALCL} \mathbf{d}$, an ALK $\mathrm{ALCL}^{-}$and a DLBCL $\mathbf{f}$ 
A K299

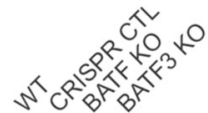

BATF - $-\infty$

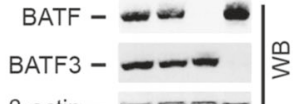

$\beta$-actin - $=00$

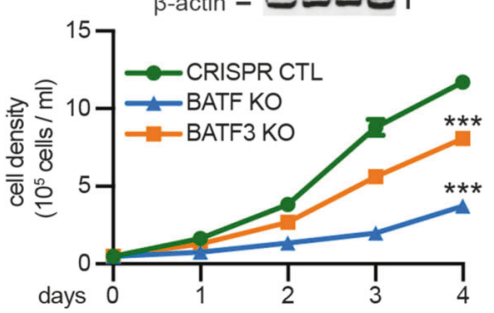

B

Mac-1

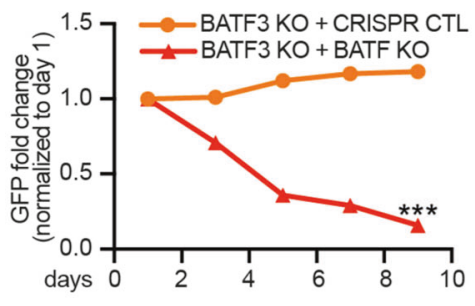

C
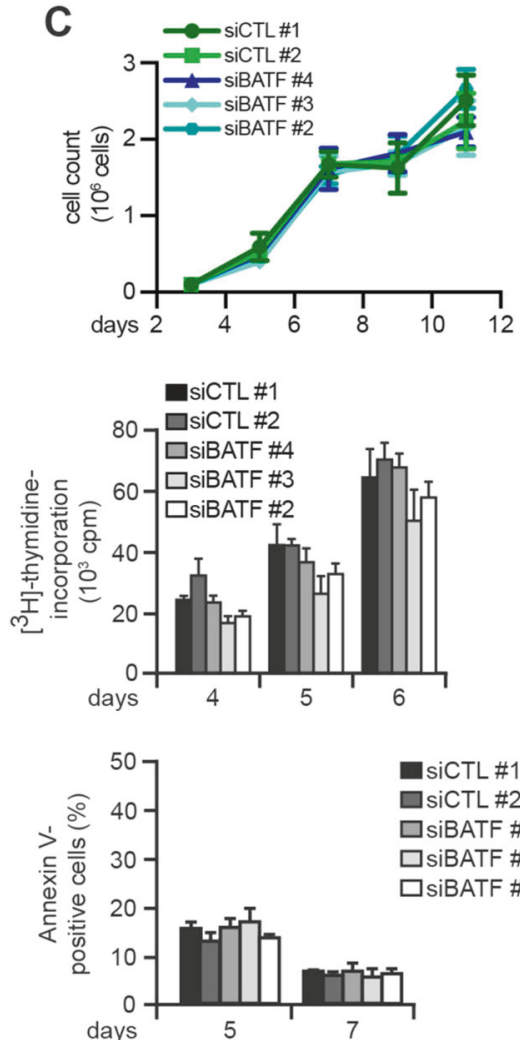

SUP-M2

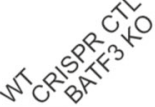

BATF -
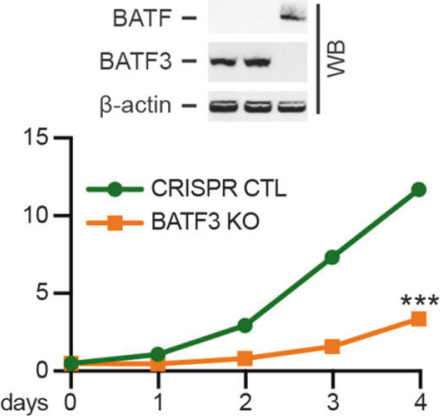

K299
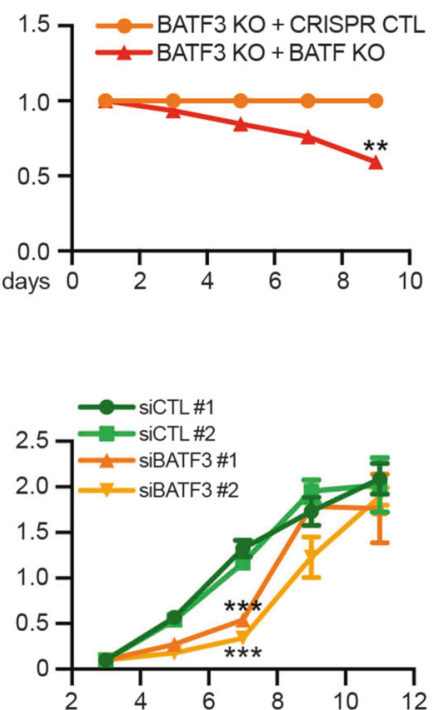

siCTL \#1

$250 \square$ SiCTL \#2
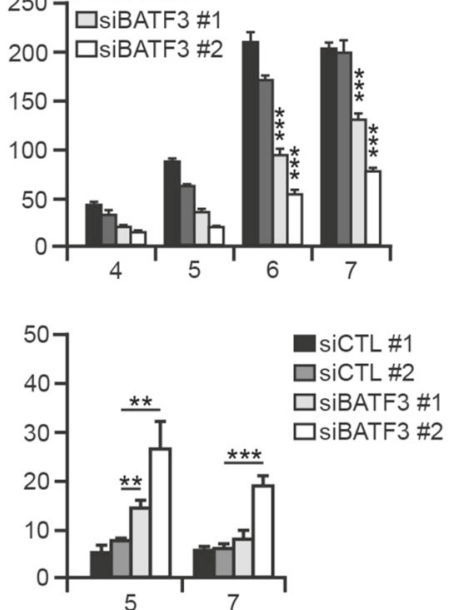

Mac-1

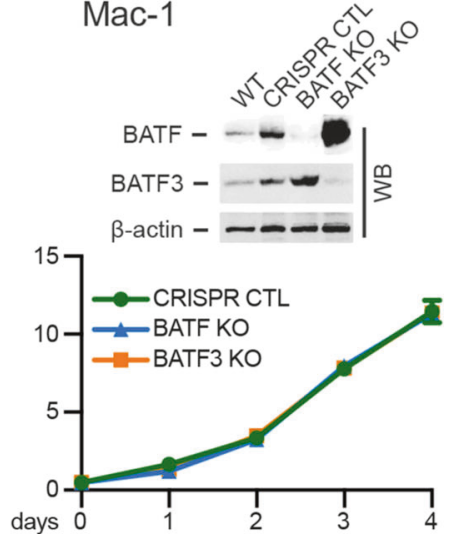

K299 xenotransplant

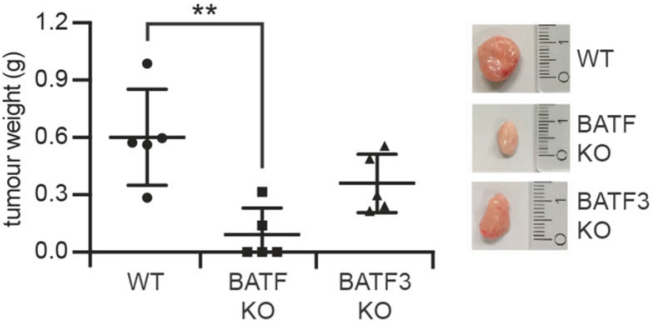

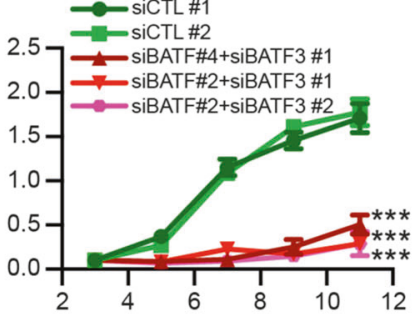
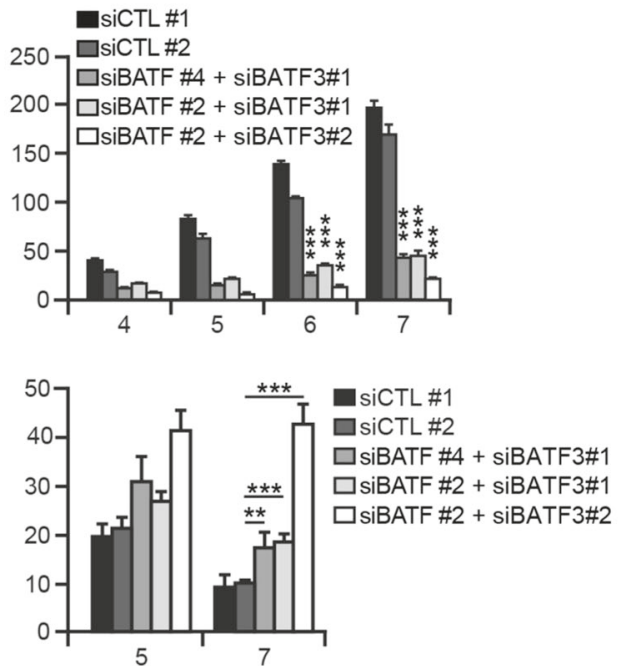
Fig. 2 CRISPR/Cas9-mediated deletion and siRNA-mediated knockdown of BATF and BATF3 in ALCL. a CRISPR/Cas9-mediated deletion of BATF and/or BATF3 in K299 (left), SUP-M2 (center) and Mac-1 (right) cells. Top, immunoblotting of wild-type (WT), controltreated (CRISPR CTL), BATF KO and/or BATF3 KO cells for BATF and BATF3. Note the compensatory increase of BATF following BATF3 deletion. Bottom, cell numbers are shown over time. b Left and center, BATF3 single knock-out Mac-1 (left) and K299 (center) cells were transduced with GFP-labeled vector encoding BATF gRNA (BATF KO) or non-targeting control (CRISPR CTL). The percentage of GFP-positive cells over time is indicated. Right, xenotransplantation of K299 WT, BATF KO and BATF3 KO cells on NSG mice. Tumor weight at day 14 is shown in gram $(\mathrm{g})$. Far right, representative tumors at day 14. c siRNA-mediated knock-down of BATF and/or BATF3 in Mac-1. Cells were treated with control siRNAs (siCTL \#1 and siCTL \#2), siRNAs targeting BATF (siBATF \#2, siBATF \#3 and siBATF \#4; left) or BATF3 (siBATF3 \#1 and siBATF3 \#2; center), or respective combinations (right). Cell numbers (top), $\left[{ }^{3} \mathrm{H}\right]-$ thymidine incorporation (center) and percentage of Annexin V-positive cells (bottom) are shown over time. ${ }^{*} P<<0.01 ; * * * P<$ $0.001 ;$ n.s., not significant

\section{High-level expression of BATF and BATF3 in ALCL}

The distinct DNA binding of BATF and BATF3 in ALCL indicated cell-type-specific expression. Indeed, BATF mRNA was largely restricted to, and BATF3 was exclusively expressed in ALCL cell lines (Fig. 1c, upper left). $B A T F 2$ was not expressed (data not shown). We confirmed high BATF and BATF3 protein expression in all ALCL cell lines (Fig. 1c, lower left, and Supplementary Figure 1C and 1D). The highest BATF levels in some $\mathrm{ALK}^{-}$cell lines corresponded to their somewhat stronger DNA binding at AICE_IL12RB (see Fig. 1a).

Immunohistochemistry of BATF and BATF3 in human lymphoma specimens demonstrated nuclear localization (Fig. 1c, right). Among 69 non-ALCL B-NHL and T-NHL, none of the mantle cell (MCL; 0/7), follicular (FL; 0/11) and Burkitt lymphomas (BL; 0/11) expressed BATF. expressed BATF, and 15 of 20 DLBCL showed varying numbers of positive lymphoma cells, whereas all CLL cases (9/9; only in proliferative centers), 2/2 NLPHL and 9/9 PTCL (NOS) were BATF positive. We concluded that BATF expression is associated with distinct lymphoma subtypes and cellular subpopulations. Importantly, strong staining was observed in 16/16 ALCL $\left(7 \mathrm{ALK}^{+} / 9 \mathrm{ALK}^{-}\right)$ (Fig. 1c right, top) and 8/8 classical Hodgkin lymphoma (cHL) cases.

BATF3 showed a more restricted expression pattern. In total, 16/16 ALCL (7 $\mathrm{ALK}^{+} / 9 \mathrm{ALK}^{-}$) (Fig. 1c right, bottom) and $8 / 8 \mathrm{cHL}$ strongly stained positive, whereas among 69 B-NHL and T-NHL (20 DLBCL, 10 MCL, 9 CLL, 11 FL, 8 BL, 9 PTCL, 2 NLPHL) only 1 CLL sample was BATF3 positive. Thus, simultaneous BATF and BATF3 expression was unique to ALCL and cHL.
CRISPR/Cas9-mediated deletion and siRNA knockdown of BATF and/or BATF3 in ALCL

We next defined the role of BATF and BATF3 in ALCL by gene-specific inactivation by CRISPR/Cas9-mediated knock-out (KO) in K299, SUP-M2 and Mac-1 cells (Figs. 2a, b). Interestingly, following BATF3 deletion, BATF was upregulated. This was also observed in SUP-M2 cells, in which BATF was virtually absent at baseline (Supplementary Figure 1D). Deletion of BATF or BATF3 in K299 (Fig. 2a, left) or BATF3 in SUP-M2 cells (Fig. 2a, center) resulted in sustained growth retardation, but did not alter the growth of Mac-1, in which we, however, observed the strongest counterregulation of BATF and BATF3 (Fig. 2a, right).

We were unable to generate BATF and BATF3 double KO ALCL cells, suggesting lethality of double BATF KO to ALCL. To test this, we monitored the fate of CRISPR/ Cas9-mediated BATF and BATF3 double KO cells by transducing BATF3 single KO cells with BATF-targeting guide-RNA (gRNA) (Fig. 2b, left and center, Supplementary Figure 2A). In Mac-1 cells, despite no effect of BATF single KO (see Fig. 2a), trans duction of BATF3 single KO cells with BATF-directed gRNA led to a rapid loss of green fluorescent protein (GFP)-positive cells. A similar, somewhat less pronounced effect was observed in K299 cells, which, however, already showed growth retardation in BATF3 single KO cells (see Fig. 2a). Finally, xenotransplantation of K299 BATF KO cells produced significantly smaller tumors compared with WT cells (Fig. 2b, right), with a similar tendency for BATF3 KO tumors.

In a complementary approach, we performed siRNAmediated knock-down of both BATFs (Fig. 2c and Supplementary Figures 2B and 2C). Single knock-down of BATF did not alter viability of Mac-1 cells (Fig. 2c, left), whereas BATF3 knock-down moderately inhibited growth and induced cell death (Fig. 2c, center). Importantly, simultaneous knock-down of both BATFs resulted in strong growth inhibition and apoptotic death (Fig. 2c, right), which reflected our inability to generate double BATF and BATF3 KO clones using CRISPR techniques. Similar results were obtained with K299 cells (Supplementary Figure 2C). As specificity control, reversion of cellular toxicity was shown by concomitant ectopic BATF and BATF3 expression (Supplementary Figure 3A).

\section{Induction of cell death following global abrogation of AP-1 DNA binding activity in ALCL}

In an independent approach, we globally inhibited AP-1 by a dominant repressor of AP-1 and leucine zipper TFs, such as BATFs, named A-Fos [36]. This complemented our approaches targeting BATFs, as BATFs have low DNA 


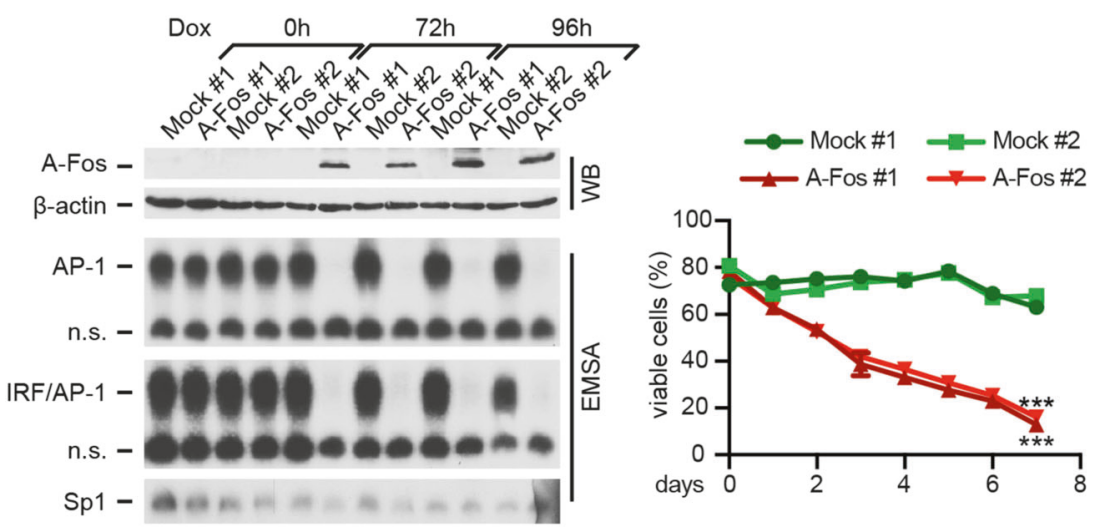

Fig. 3 Inhibition of global AP-1 activity by its dominant-negative AFos in FE-PD cells. Inducible A-Fos expression abrogates constitutive AP-1. Left, analysis of enriched GFP-positive cells by WB for A-Fos expression (top; FLAG antibody) and EMSA for DNA binding to TRE site (center, top) and BCL 11b AICE (center, bottom) after Dox

affinity and require JUN proteins, mainly JUNB, for heterodimer formation and DNA binding [28]. We generated Dox-inducible A-Fos FE-PD cells (Fig. 3 and Supplementary Figure 3B), in which AP-1 activity was virtually abolished following Dox addition (Fig. 3, left). This inhibited cell growth (Supplementary Figure 3B) and induced cell death (Fig. 3, right). Similar results were obtained following transient A-Fos expression in K299 (Supplementary Figure 3C). Thus, constitutive AP-1/BATF activity is essential for viability of $\mathrm{ALK}^{+}$and $\mathrm{ALK}^{-} \mathrm{ALCL}$ cells.

\section{ALCL shows a gene expression pattern characteristic for TH17 and ILC3 cells}

JUN-BATF, IRF4 and STAT3 coordinate TH17 gene expression [33]. As all these TFs are active in ALCL, we hypothesized that their combined activity imposes a TH17 cellular fate in ALCL. Indeed, ALCL cell lines consistently expressed TH17-associated genes (Fig. 4a), including $A H R$, ILIRI, ILAR, IL18RI, IL22, IL23R and IL26. Given the absence of T-cell receptor (TCR) rearrangement in a (minor) subset of ALCL cases [41, 42], we reasoned that ALCL cells could be derived alternatively from ILC 3 cells. These cells are characterized by the absence of BCR or TCR gene rearrangements and have, compared with TH17 cells, an overlapping but distinct gene expression pattern [35].

To test whether a TH17- or ILC3-like signature was an inherent feature of the overall ALCL expression pattern, we performed GSEAs (Fig. 4b, top). Based on published gene expression data [35], we defined TH17 and ILC3 signatures, using the top 100 up- or downregulated genes compared with TH1 cells. Our ALCL cell lines significantly enriched genes upregulated in TH17 cells (Fig. 4b, top, left) and even more prominently ILC3-upregulated genes (Fig. 4b, top, addition for the indicated times. $\beta$-Actin and Sp1 DNA binding were controls. Two independent experiments (\#1 and \#2) are shown. Right, percentage of viable cells following Dox induction measured by PI staining and flow cytometry over time. ${ }^{* * *} P<0.001$

right). ILC3 signature leading edge genes are shown in Supplementary Table 3. Consistently, principal component analysis (PCA) of $\mathrm{ALK}^{+}$(K299, SU-DHL-1, DEL, JB6), $\mathrm{ALK}^{-}$(FE-PD, Mac-2A) and control (T; Jurkat, KE-37, Molt-14, H9) samples based on the top 100 differentially expressed genes between TH17 and ILC3 and TH1 signatures revealed a clear separation of ALCL and control cells along PC1 (Fig. 4b, bottom). Moreover, ALCL cells were localized closer to projected ILC3, again more significant for ILC3 signatures $(P$-values $\leq 1.6 \mathrm{E}-9$ for TH17 signature based PCA and 9.5E-17 for ILC3). This suggested an in-between localization of ALCL between the ILC3 and TH17 phenotypes with a stronger skewing towards an ILC3 profile.

\section{Expression of TH17/ILC3 genes in primary ALCL; IL- 22, IL-17A and IL-17F are secreted by ALCL cell lines, IL-17A and IL-17F detectable in ALCL patients}

We next aimed to confirm expression of TH17- and ILC3associated genes in primary lymphomas. In the majority of primary ALCL samples, TH17-/ILC3 genes were much stronger or even exclusively expressed compared with NHL controls (Supplementary Figure 4A). Moreover, IL-22 was secreted by three $\mathrm{ALK}^{-}$cell lines and IL-17A and IL-17F by several ALCL cell lines (Supplementary Figure 4B). IL$17 \mathrm{~A}$ was detectable in three of 21 pretreatment serum/ plasma samples of $\mathrm{ALK}^{+}$ALCL patients and one healthy control, whereas it was undetectable in patients in remission (Supplementary Figure 4C) $(P=0.48)$. IL-17F levels were high in 4 of 21 ALCL patients, whereas no healthy control or patient in remission exhibited measurable IL-17F (Supplementary Figure 4C). Although there was only a tendency toward a higher mean IL-17F level in $\mathrm{ALK}^{+}$ALCL patients $(P=0.08)$, these data suggest specific IL-17F upregulation 

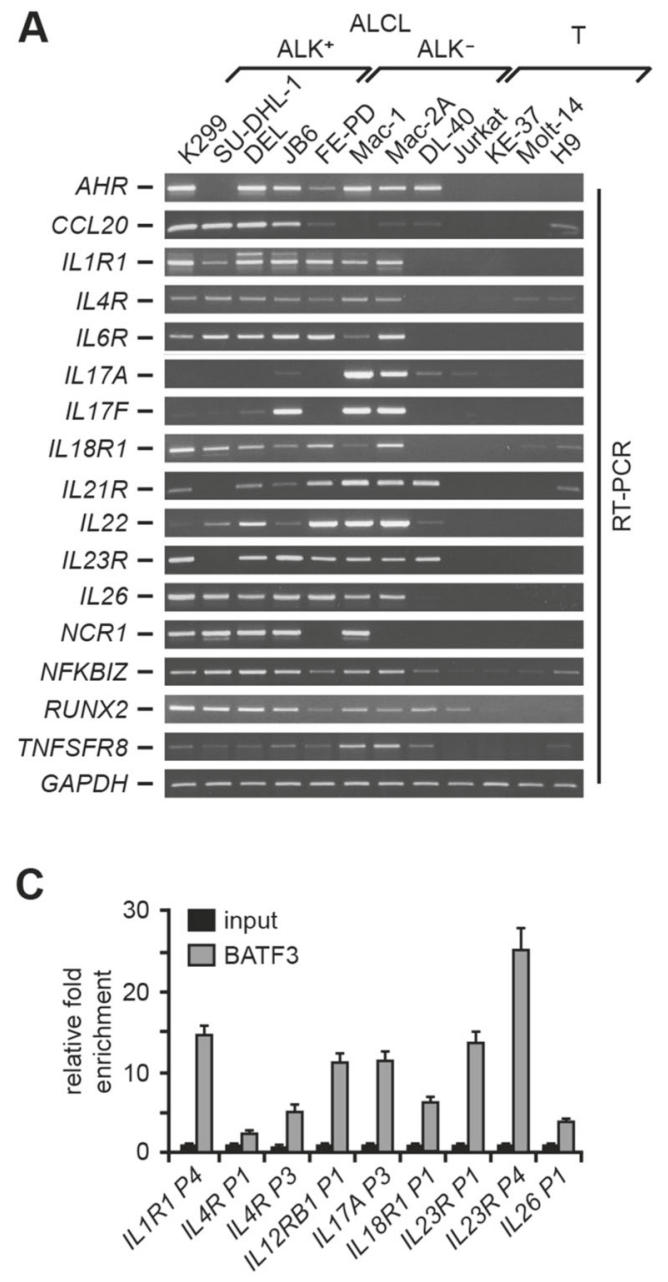

D

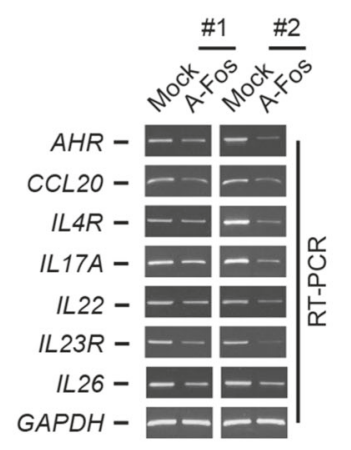

B
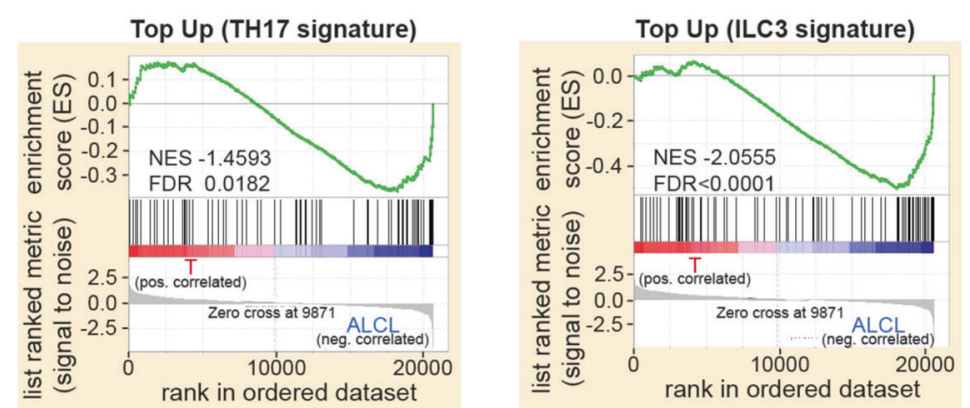

- enrichment profile $\boldsymbol{C}$ hits - ranking metric scores
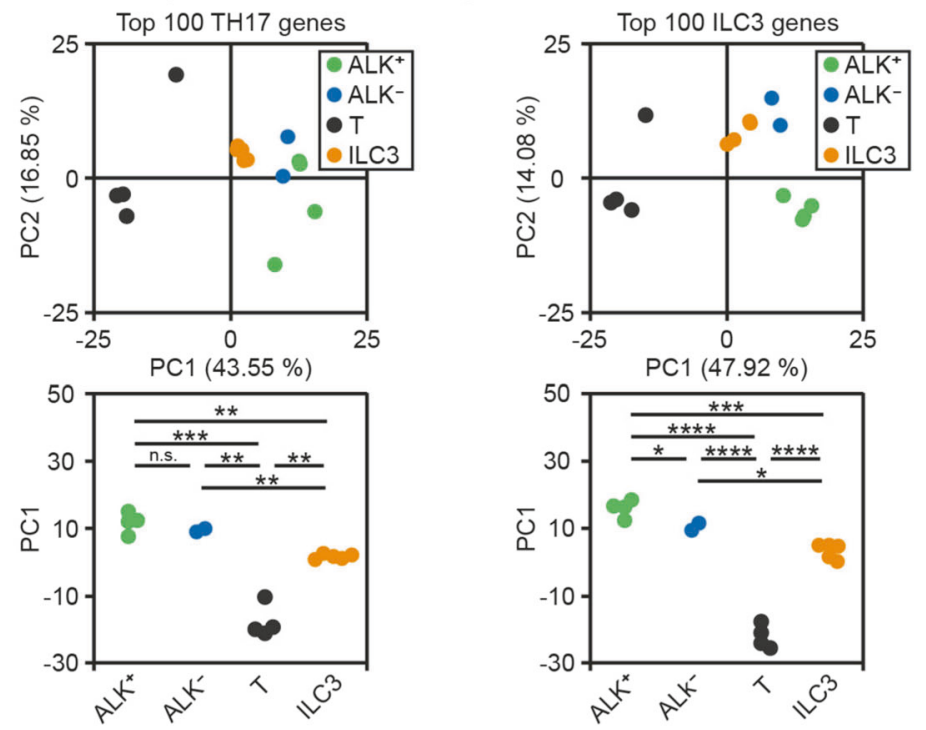

$\mathbf{E}$

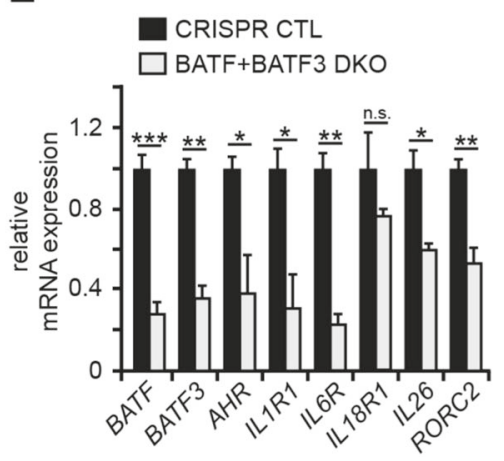

in distinct $\mathrm{ALK}^{+} \mathrm{ALCL}$ patients. We did not observe a significant correlation with other clinical or biological parameters (data not shown).

\section{Recruitment of BATFs and JUNB to regulatory regions of TH17/ILC3 genes and dependency of TH17/ILC3 genes on AP-1/BATFs in ALCL}

A direct regulation of TH17-/ILC3-associated genes by AP1/BATF was investigated by ChIPs of BATF, BATF3 and
JUNB. We analyzed promoter or enhancer regions of IL1R1, IL4R, IL12RB, IL17A, IL18R1, IL22, IL23R and IL26 in three ALCL cell lines and Jurkat controls (Fig. 4c and Supplementary Figure 5A and 5B). Most of the regulatory regions showed strong BATF, BATF3 and JUNB recruitment in ALCL cells, which was not observed in Jurkat. Functionally, we confirmed AP-1 involvement in the upregulation of TH17/ILC3 genes, as expression of $A H R$, CCL20, ILAR, IL17A, IL22, IL23R and IL26 decreased following AP-1 inhibition (Fig. 4d). Furthermore, 
Fig. 4 TH17/ILC3 gene expression in ALCL and link to the deregulated BATF/BATF3/AP-1 activity. a mRNA expression of TH17/ ILC3-associated genes and, as control, GAPDH were analyzed by RTPCR. b More global approaches to TH17/ILC3 gene expression in ALCL. Upper panels, GSEA of differentially expressed genes between ALCL (K299, SU-DHL-1, DEL, JB6, FE-PD, Mac-2A) and T control (T) cell lines (Jurkat, KE-37, Molt-14, H9) based on TH17 (left) and ILC3 (right) top 100 upregulated genes. Lower panels, PC analyses of $\mathrm{ALK}^{+}$and $\mathrm{ALK}^{-} \mathrm{ALCL}$ and $\mathrm{T}$ control samples based on 100 top differentially expressed TH17 (left) or ILC3 (right) genes, separating ALCL and T-cell lines along the PC1 axis. PCAs were supplemented by projection of ILC3 samples [45]. n.s., not significant; $* P \leq 0.05$; $* * P \leq 0.01 ; * * * P \leq 0.001 ; * * * * P \leq 0.0001$. c BATF3 ChIP from K299 cells. Input and precipitated DNA were amplified by qPCR for the indicated promoter or enhancer regions. Combined data of two biological replicates are shown as mean \pm SEM. d Inhibition of AP-1 downregulates TH17/ILC3 genes. Enriched A-Fos or Mock transfected K299 cells were analyzed by RT-PCR for TH17/ILC3 genes. Two (\#1 and \#2) of four independent experiments are shown. e Analysis of TH17/ILC3 genes in K299 cells with double BATF and BATF3 KO at day 13 following lentiviral transduction. qPCR-based expression of the indicated genes in control cells (CRISPR CTL) or cells transduced with a combination of sgRNAs targeting BATF and BATF3 (BATF + BATF3 DKO). BATF and BATF3 were analyzed to verify their KO. The expression level in CRISPR CTL cells was set 1 . Error bars denote $95 \%$ CIs. One out of three independent experiments is shown. $* P \leq 0.05 ; * * P \leq 0.01 ; * * * P \leq 0.001$; n.s., not significant

K299 showed decreased expression of $A H R, I L 1 R 1, I L 6 R$, IL26 and RORC2 after enrichment of cells with simultaneous gRNA-mediated double KO of BATF and BATF3 at day 13 after transduction (Fig. 4e).

\section{Primary ALCL shows a gene expression pattern characteristic for ILC3, while taking an intermediate position between two groups of PTCL with respect to TH17 signature genes}

To globally approach the concept of TH17/ILC3 skewing of primary ALCL, we performed GSEA with microarray data of primary ALCL and PTCL samples used in previous studies (Fig. 5) [38-40]. A correlation analysis of gene expression profiles of all samples (bracket [a]) demonstrated one central ALCL cluster flanked by two distinct PTCL clusters, positioned in bracket [b] and [c] of Fig. 5a. In an overall analysis including all samples (Fig. 5a, bracket [a]), the ILC3 signature enriched in ALCL (Fig. 5b, center top panel). In contrast, the TH17 signature demonstrated a trend toward an enrichment in PTCL (Fig. 5b, center bottom panel). The GSEA between both PTCL clusters revealed a strong TH17 signature enrichment in PTCLs positioned in bracket [b] compared with those positioned in bracket [c] (NES 3.2556; FDR <0.0001; data not shown). The TH17like PTCL in bracket [b] also showed an enrichment of the TH17 signature when compared with ALCL (Fig. 5b, left bottom). The ALCL, however, showed an enrichment of the TH17 signature when compared with PTCLs positioned in bracket [c] (Fig. 5b, right bottom). The ILC3 signature was enriched in ALCL when compared with any of the PTCL clusters (Fig. 5b, top). We concluded that gene expression pattern characteristic for ILC3 is a common feature of ALCL, whereas, regarding TH17 signature genes, ALCL takes an intermediate position between PTCL with or without expression of TH17 genes.

\section{Expression of RORC2 (RORyt) in ALCL; RORC inhibition results in cell death induction in $A L C L$ and synergizes with ALK inhibitors}

TH17 and ILC3 cells are characterized by a unique expression of RORC2, also known as ROR $\gamma \mathrm{t}$ [43-45, 46]. RORC2 mRNA was detectable in five of eight ALCL cell lines, but none of the controls (Fig. 6a, upper left). RORC1 mRNA was stronger expressed in ALCL cell lines. At the protein level, we confirmed RORC overexpression and RORC2 restriction to ALCL cell lines (Fig. 6a, lower left, and Supplementary Figure 5C, left). Furthermore, robust RORC2 mRNA expression was detectable in most primary ALCL specimens in contrast to NHL, including five PTCLNOS (Supplementary Figure 5C, center and right). Functionally, RORC2 expression decreased following AP-1/ BATF inhibition by A-Fos (Fig. 6a, right).

Finally, we investigated the effect of pharmacological RORC inhibition in ALCL. Treatment of ALCL cell lines with the inhibitory RORC modulators SR2211 (ref. 47) and SR1903 (a close analog of SR2211) resulted in decreased viable cells over time (Fig. 6b, top), whereas no effect was observed in cells without (KE-37) or low level (Jurkat) RORC expression and in FE-PD cells with RORC1 but no RORC2 expression (Fig. 6b, bottom). Moreover, we investigated the effect of RORC inhibitors SR2211, SR1903 and GSK805 (ref. 48) in combination with ALK inhibition in the $\mathrm{ALK}^{+}$ALCL cell lines K299, DEL and JB6 (Fig. 6c). The combination of crizotinib with RORC inhibitors enhanced cell death induction.

\section{Discussion}

We demonstrate that $\mathrm{ALK}^{+}$and $\mathrm{ALK}^{-} \mathrm{ALCL}$ are characterized by an unprecedented activation of the AP-1 family and leucine zipper TFs BATF and BATF3, and that simultaneous high-level expression of both BATFs is a particular feature of ALCL. In accordance with the fact that BATF3 distinguishes ALCL from other PTCL [26, 27], BATF and BATF3 thus add a new layer of complexity to deregulated AP-1 in ALCL [14, 18, 19]. Remarkably, although NPM-ALK induces JUNB [21], $\mathrm{ALK}^{+}$and $\mathrm{ALK}^{-}$ ALCL neither differ in their global AP-1 activity nor in expression of distinct AP-1 factors [refs. 14, 18, 19 and this 
A

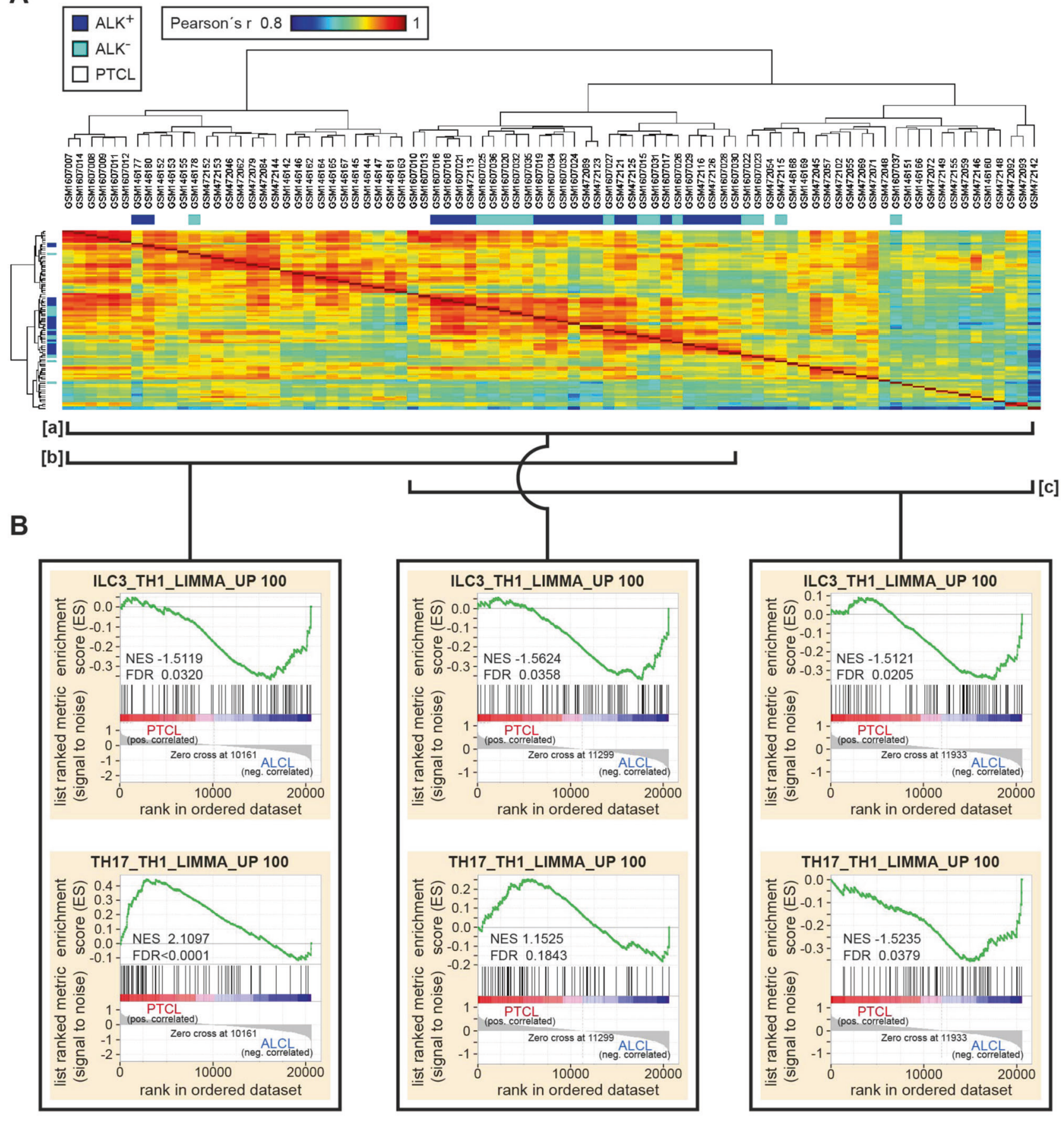

- enrichment profile - hits - ranking metric scores

Fig. 5 TH17/ILC3 gene set enrichment analyses of primary ALCL and PTCL. a Pearson correlation heatmap between ALCL and PTCL samples. Samples are clustered by the Euclidean distance and separate into three major clusters. b GSEA of ALCL and PTCL samples from

work], which supports our hypothesis that they share a common pathogenic mechanism $[49,50]$. In favor of this, the epigenome between $\mathrm{ALK}^{+}$and $\mathrm{ALK}^{-} \mathrm{ALCL}$ is highly similar [49]. Apart from ALCL, we identified a concomitant expression of BATF and, as only recently demonstrated indicated clusters, marked by brackets underneath the heatmap shown in a. Note, although ALCL shows an overall enrichment of the ILC3 signature (GSEA of upper row), the TH17 signature enrichment (GSEA of lower row) is decreasing from left to the right

[27], BATF3 in cHL, which is in line with the in cHL known constitutive AP-1 activity and shared key TF activities in cHL and ALCL [16, 18, 19].

AP-1 forms homo- or heterodimers and exerts cell-type and differentiation stage-specific functions [51]. 

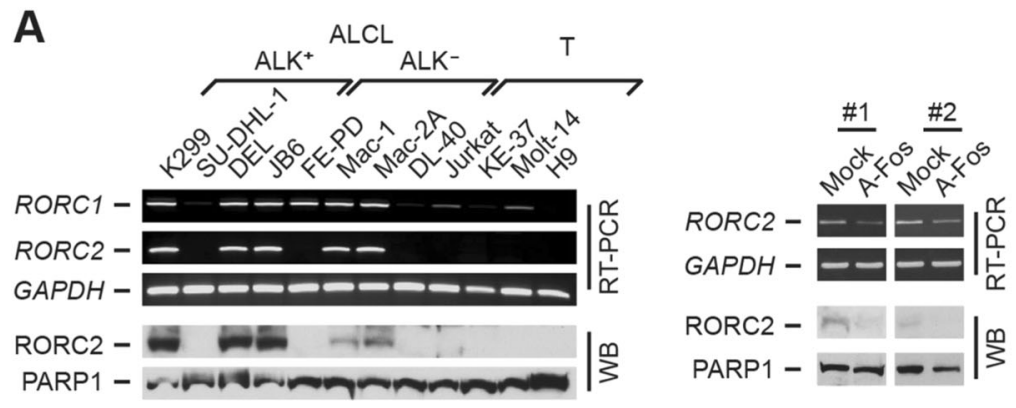

B
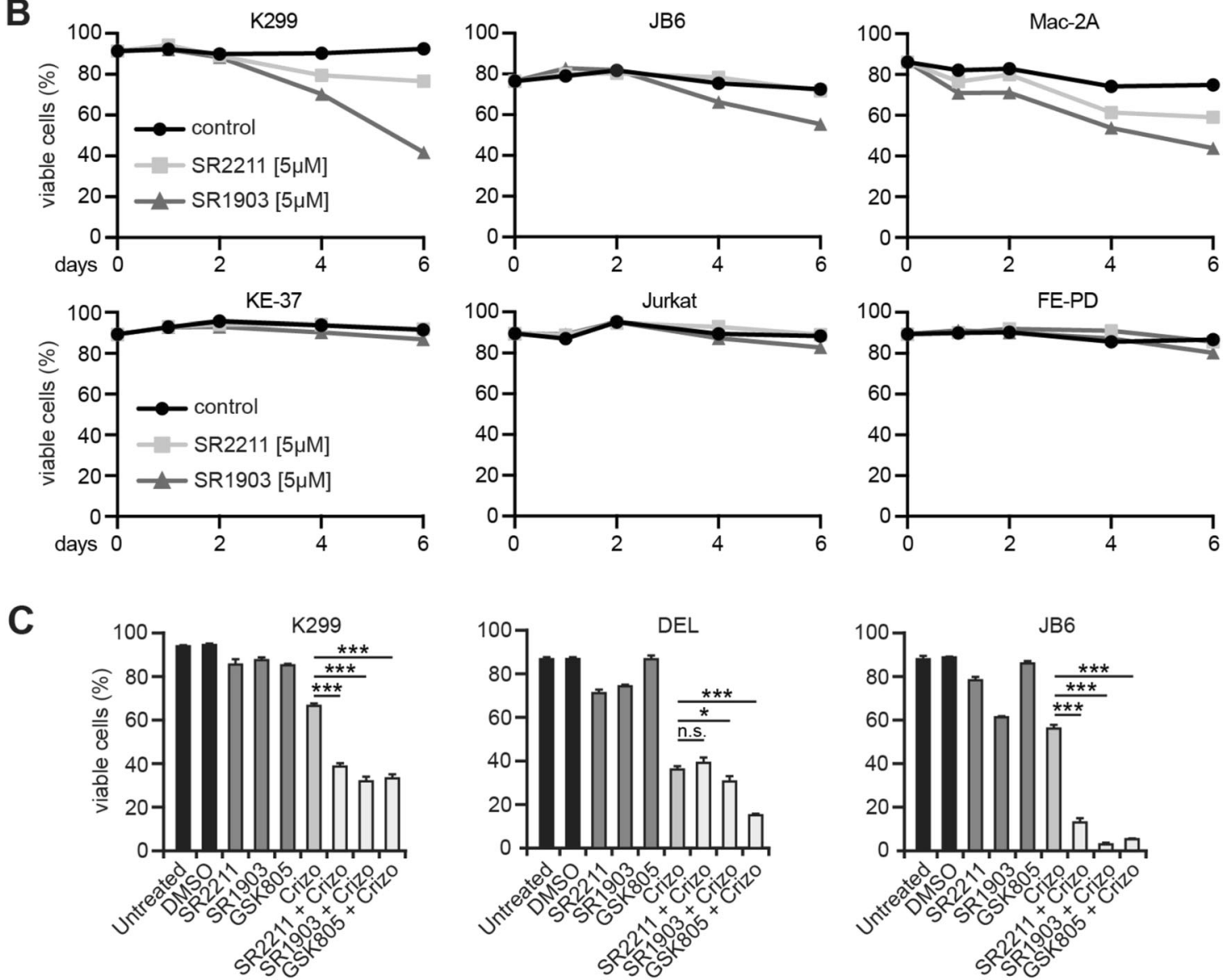

Fig. 6 Expression and inhibition of RORC2 in ALCL. a Left, analysis of RORC1 and RORC2 mRNA by RT-PCR (top) and RORC protein expression by immunoblotting of nuclear extracts (bottom). GAPDH and PARP1 are controls. Right, AP-1 inhibition downregulates RORC2. K299 cell were treated as in Fig. 4d, and RORC2 and GAPDH mRNA were analyzed by RT-PCR (top), and RORC2 expression changes at the protein level by WB (bottom). Two (\#1 and \#2) of four independent experiments are shown. b RORC inhibition by small compounds induces cell death of ALCL cell lines. Cells were treated with $5 \mu \mathrm{M}$ of RORC inhibitors SR2211 or SR1903, or the control (DMSO), and the percentage of viable cells was analyzed by PI

Furthermore, AP-1 effects certainly differ between transient and the long-term activation observed in ALCL, as known, for example, NF- $\mathrm{KB}$ [52]. We present evidence that BATF and BATF3 are essential components of the TF network in staining. One of three independent experiments is shown. (c) Enforced cell death induction by crizotinib in combination with RORC inhibitors. The $\mathrm{ALK}^{+}$cell lines K299, DEL and JB6 cells were left untreated, or treated with DMSO control, the RORC inhibitors SR2211 $(7.5 \mu \mathrm{M})$, SR1903 $(7.5 \mu \mathrm{M})$ and GSK805 $(7.5 \mu \mathrm{M})$, or $25 \mathrm{nM}$ crizotinib (Crizo) alone, or the different RORC inhibitors together with crizotinib. Cell death was analyzed by Annexin V-FITC/PI staining. The percentage of viable cells is shown. Experiments were performed in triplicates and results are shown as mean $\pm \mathrm{SD}$. One of three independent experiments is shown. $* P<0.05$; $* * P<0.001$; n.s., not significant

ALCL. First, deletion of BATF or BATF3 caused growth retardation in vitro and in vivo, in line with a recently published study on BATF3 in ALCL [27]. Our inability to generate BATF and BATF3 double $\mathrm{KO}$ cells indicates 
lethality of combined BATF deletion. Second, we observed a comparable phenotype with siRNA-mediated BATF knock-down, in which the combined BATF and BATF3 knock-down resulted in pronounced growth arrest and cell death induction. The cross-regulation of BATF and BATF3 detected in our cell lines and in genetically manipulated mice and a functional redundancy $[28,29]$ might attenuate effects of targeting single BATFs. BATFs modify transcriptional activity by interaction with AP-1 TFs like JUNB and JUN [28], both highly activated in ALCL [18, 24]. In line with their concerted activity, global AP-1 inhibition caused death of ALCL cells (this work and ref. 18).

Furthermore, we describe a composite DNA binding activity at AICEs with IRF4, which is known from TH17 cells [30, 32-34]. In $\mathrm{ALK}^{+}$ALCL, expression of some TH17 genes has been reported [40, 53, 54], and NPM-ALKinduced miR-135b enforces IL-17 production [54]. We demonstrate that $\mathrm{TH} 17$ gene expression is a unifying feature of $\mathrm{ALK}^{+}$and $\mathrm{ALK}^{-} \mathrm{ALCL}$, and their expression depends at least in part on AP-1/BATFs. By a comprehensive analysis of the TH17 signature in primary ALCL and PTCL, we identified two PTCL groups, one with strong TH17 signature and one without, whereas ALCL were taking an intermediate position between these PTCL groups. Whereas the biological and clinical relevance of TH17 gene expression in PTCL has to be investigated in future studies, these data confirmed partial TH17 skewing of primary ALCL.

Remarkably, the ILC3 gene set, which overlaps with that of TH17 cells [35], showed a consistent enrichment in ALCL, irrespective of the PTCL comparison. This is of particular relevance regarding the cellular origin of ALCL and opens a new view on ALCL pathogenesis. Approximately $14 \%$ of ALCL show germline TCR configuration [41]. The absence of BCR or TCR rearrangements is as much a hallmark of ILC3 as the lack of typical B or T-cell markers [55, 56]. ILC3 are enriched in human tonsils and the intestinal lamina propria, and circulate in the peripheral blood [55]. Whereas nearly all known hematopoietic cell types give rise to malignancies, no ILC3-derived neoplasm is currently known. We propose that a (minor) subfraction of ALCL originates from ILC3. The expression of key ILC3 genes, the lack of B or T lymphoid surface markers, the lack of a genomic lymphoid fingerprint in an ALCL fraction and the frequent expression of IL-22 [53, 57] are in accordance with such a hypothesis. Alternatively, the deregulated TF network might superimpose a TH17/ILC3 cellular fate on ALCL cells.

Our work provides new aspects for targeted treatment strategies for ALCL. Inhibitors of TH17 cells are developed due to TH17 cell involvement in autoimmune and inflammatory diseases [58, 59-61]. Hence, interference with TH17 gene activity might represent a treatment strategy for
$\mathrm{ALK}^{+}$and $\mathrm{ALK}^{-}$ALCL. Among $\mathrm{ALK}^{+}$ALCL patients, treatment with ALK inhibitors exerts long-term disease control [62], but is obviously unable to eradicate the respective lymphoma clone [63]. The synergistic activity of RORC inhibitors together with ALK inhibitors might eradicate persisting ALCL cells. In addition, we provide the basis for exploring interference with, for example, IL-17 and IL-26 circuits and further evaluation of TH17-related cytokines as diagnostic and prognostic markers for ALCL, as also suggested by an independent study [53].

Overall, we have identified BATF and BATF3 as essential components of the gene regulatory network in ALCL and have demonstrated their pathogenic and therapeutic relevance. Furthermore, we suggest that a subset of ALCL originate from ILC3, a finding that has to be elaborated in future studies.

Acknowledgements We thank Simone Lusatis (Berlin) and Brigitte Wollert-Wulf (Berlin) for outstanding technical assistance, Peter Rahn (Berlin) for cell sorting, Dan Littman (New York) for providing RORC antibody and helpful discussion and Georg Bornkamm for helpful discussion. This work was supported in part by grants from the Deutsche Forschungsgemeinschaft to SM and MJ (MA 3313/2-1 and JA 1847/2-1), the Experimental and Clinical Research Center, a joint cooperation between the Charité-Universitätsmedizin Berlin and the MDC, the German Cancer Consortium (DKTK), the Berlin School of Integrative Oncology (BSIO), the Jubiläumsfond der Österreichischen Nationalbank (OM, no. 14856), the Austrian Science Fund (LK, P26011 and 29251), and the Forschungshilfe Peiper (WW and CD-W). MC, LK, H-CL, OM, SM, SDT, WW and CD-W have received funding from the European Union's Horizon 2020 research and innovation program under the Marie Skłodowska-Curie grant agreement no. 675712 .

\section{Compliance with ethical standards}

Conflict of interest The authors declare that they have no conflict of interest.

Open Access This article is licensed under a Creative Commons Attribution-NonCommercial-ShareAlike 4.0 International License, which permits any non-commercial use, sharing, adaptation, distribution and reproduction in any medium or format, as long as you give appropriate credit to the original author(s) and the source, provide a link to the Creative Commons license, and indicate if changes were made. If you remix, transform, or build upon this article or a part thereof, you must distribute your contributions under the same license as the original. The images or other third party material in this article are included in the article's Creative Commons license, unless indicated otherwise in a credit line to the material. If material is not included in the article's Creative Commons license and your intended use is not permitted by statutory regulation or exceeds the permitted use, you will need to obtain permission directly from the copyright holder. To view a copy of this license, visit http://creativecommons. org/licenses/by-nc-sa/4.0/.

\section{References}

1. Rui L, Schmitz R, Ceribelli M, Staudt LM. Malignant pirates of the immune system. Nat Immunol. 2011;12:933-40. 
2. Shaffer AL 3rd, Young RM, Staudt LM. Pathogenesis of human B cell lymphomas. Ann Rev Immunol. 2012;30:565-610.

3. Stein H, Foss HD, Dürkop H, Marafioti T, Delsol G, Pulford K, et al. $\mathrm{CD} 30(+)$ anaplastic large cell lymphoma: a review of its histopathologic, genetic, and clinical features. Blood. 2000;96:3681-95.

4. Piccaluga PP, Gazzola A, Mannu C, Agostinelli C, Bacci F, Sabattini E, et al. Pathobiology of anaplastic large cell lymphoma. Adv Hematol. 2010, Article ID 345053, 10 pages.

5. Swerdlow SH, Campo E, Pileri SA, Harris NL, Stein H, Siebert R, et al. The 2016 revision of the World Health Organization classification of lymphoid neoplasms. Blood. 2016;127:2375-90.

6. Chiarle R, Voena C, Ambrogio C, Piva R, Inghirami G. The anaplastic lymphoma kinase in the pathogenesis of cancer. Nat Rev Cancer. 2008;8:11-23.

7. Crescenzo R, Abate F, Lasorsa E, Tabbo F, Gaudiano M, Chiesa $\mathrm{N}$, et al. Convergent mutations and kinase fusions lead to oncogenic STAT3 activation in anaplastic large cell lymphoma. Cancer Cell. 2015;27:516-32.

8. Mereu E, Pellegrino E, Scarfo I, Inghirami G, Piva R. The heterogeneous landscape of ALK negative ALCL. Oncotarget. 2017;8:18525-36.

9. Lamant L, de Reynies A, Duplantier MM, Rickman DS, Sabourdy F, Giuriato S, et al. Gene-expression profiling of systemic anaplastic large-cell lymphoma reveals differences based on ALK status and two distinct morphologic ALK + subtypes. Blood. 2007;109:2156-64.

10. Merkel O, Hamacher F, Laimer D, Sifft E, Trajanoski Z, Scheideler $\mathrm{M}$, et al. Identification of differential and functionally active miRNAs in both anaplastic lymphoma kinase (ALK) + and ALKanaplastic large-cell lymphoma. Proc Natl Acad Sci USA. 2010;107:16228-33.

11. Boi M, Rinaldi A, Kwee I, Bonetti P, Todaro M, Tabbo F, et al. PRDM1/BLIMP1 is commonly inactivated in anaplastic large Tcell lymphoma. Blood. 2013;122:2683-93.

12. Eckerle S, Brune V, Döring C, Tiacci E, Bohle V, Sundstrom C, et al. Gene expression profiling of isolated tumour cells from anaplastic large cell lymphomas: insights into its cellular origin, pathogenesis and relation to Hodgkin lymphoma. Leukemia. 2009;23:2129-38.

13. Weilemann A, Grau M, Erdmann T, Merkel O, Sobhiafshar U, Anagnostopoulos I, et al. Essential role of IRF4 and MYC signaling for survival of anaplastic large cell lymphoma. Blood. 2015;125:124-32.

14. Mathas S, Kreher S, Meaburn KJ, Jöhrens K, Lamprecht B, Assaf $\mathrm{C}$, et al. Gene deregulation and spatial genome reorganization near breakpoints prior to formation of translocations in anaplastic large cell lymphoma. Proc Natl Acad Sci USA. 2009;106:5831-6.

15. Falini B, Fizzotti M, Pucciarini A, Bigerna B, Marafioti T, Gambacorta M, et al. A monoclonal antibody (MUM1p) detects expression of the MUM1/IRF4 protein in a subset of germinal center B cells, plasma cells, and activated $\mathrm{T}$ cells. Blood. 2000;95:2084-92.

16. Jundt F, Anagnostopoulos I, Förster R, Mathas S, Stein H, Dörken B. Activated Notch1 signaling promotes tumor cell proliferation and survival in Hodgkin and anaplastic large cell lymphoma. Blood. 2002;99:3398-403.

17. Chiarle R, Simmons WJ, Cai H, Dhall G, Zamo A, Raz R, et al. Stat3 is required for ALK-mediated lymphomagenesis and provides a possible therapeutic target. Nat Med. 2005;11:623-9.

18. Mathas S, Hinz M, Anagnostopoulos I, Krappmann D, Lietz A, Jundt F, et al. Aberrantly expressed c-Jun and JunB are a hallmark of Hodgkin lymphoma cells, stimulate proliferation and synergize with NF-kappa B. EMBO J. 2002;21:4104-13.

19. Janz M, Hummel M, Truss M, Wollert-Wulf B, Mathas S, Jöhrens $\mathrm{K}$, et al. Classical Hodgkin lymphoma is characterized by high constitutive expression of activating transcription factor 3 (ATF3), which promotes viability of Hodgkin/Reed-Sternberg cells. Blood. 2006;107:2536-9.

20. Hsu FY, Johnston PB, Burke KA, Zhao Y. The expression of CD30 in anaplastic large cell lymphoma is regulated by nucleophosmin-anaplastic lymphoma kinase-mediated JunB level in a cell type-specific manner. Cancer Res. 2006;66:9002-8.

21. Leventaki V, Drakos E, Medeiros LJ, Lim MS, Elenitoba-Johnson KS, Claret FX, et al. NPM-ALK oncogenic kinase promotes cellcycle progression through activation of JNK/cJun signaling in anaplastic large-cell lymphoma. Blood. 2007;110:1621-30.

22. Turner SD, Yeung D, Hadfield K, Cook SJ, Alexander DR. The NPM-ALK tyrosine kinase mimics TCR signalling pathways, inducing NFAT and AP-1 by RAS-dependent mechanisms. Cell Signal. 2007;19:740-7.

23. Mao X, Orchard G, Lillington DM, Russell-Jones R, Young BD, Whittaker SJ. Amplification and overexpression of JUNB is associated with primary cutaneous T-cell lymphomas. Blood. 2003;101:1513-9.

24. Schiefer AI, Vesely P, Hassler MR, Egger G, Kenner L. The role of AP-1 and epigenetics in ALCL. Front Biosci. 2015;7:226-35.

25. Laimer D, Dolznig H, Kollmann K, Vesely PW, Schlederer M, Merkel $\mathrm{O}$, et al. PDGFR blockade is a rational and effective therapy for NPM-ALK-driven lymphomas. Nat Med. 2012;18:1699-704.

26. Agnelli L, Mereu E, Pellegrino E, Limongi T, Kwee I, Bergaggio E, et al. Identification of a 3-gene model as a powerful diagnostic tool for the recognition of ALK-negative anaplastic large-cell lymphoma. Blood. 2012;120:1274-81.

27. Lollies A, Hartmann S, Schneider M, Bracht T, Weiss AL, Arnolds J, et al. An oncogenic axis of STAT-mediated BATF3 upregulation causing MYC activity in classical Hodgkin lymphoma and anaplastic large cell lymphoma. Leukemia. 2017; https://doi.org/10.1038/leu.2017.203. [Epub ahead of print].

28. Murphy TL, Tussiwand R, Murphy KM. Specificity through cooperation: BATF-IRF interactions control immune-regulatory networks. Nat Rev Immunol. 2013;13:499-509.

29. Tussiwand R, Lee WL, Murphy TL, Mashayekhi M, Kc W, Albring JC, et al. Compensatory dendritic cell development mediated by BATF-IRF interactions. Nature. 2012;490:502-7.

30. Schraml BU, Hildner K, Ise W, Lee WL, Smith WA, Solomon B, et al. The AP-1 transcription factor Batf controls T(H)17 differentiation. Nature. 2009;460:405-9.

31. Li P, Spolski R, Liao W, Wang L, Murphy TL, Murphy KM, et al. BATF-JUN is critical for IRF4-mediated transcription in T cells. Nature. 2012;490:543-6.

32. Glasmacher E, Agrawal S, Chang AB, Murphy TL, Zeng W, Vander Lugt B, et al. A genomic regulatory element that directs assembly and function of immune-specific AP-1-IRF complexes. Science. 2012;338:975-80.

33. Ciofani M, Madar A, Galan C, Sellars M, Mace K, Pauli F, et al. A validated regulatory network for Th17 cell specification. Cell. 2012;151:289-303.

34. Hasan Z, Koizumi SI, Sasaki D, Yamada H, Arakaki N, Fujihara $\mathrm{Y}$, et al. JunB is essential for IL-23-dependent pathogenicity of Th17 cells. Nat Commun. 2017;8:15628.

35. Koues OI, Collins PL, Cella M, Robinette ML, Porter SI, Pyfrom $\mathrm{SC}$, et al. Distinct gene regulatory pathways for human innate versus adaptive lymphoid cells. Cell. 2016;165:1134-46.

36. Olive M, Krylov D, Echlin DR, Gardner K, Taparowsky E, Vinson C. A dominant negative to activation protein-1 (AP1) that abolishes DNA binding and inhibits oncogenesis. J Biol Chem. 1997;272:18586-94.

37. Bornkamm GW, Berens C, Kuklik-Roos C, Bechet JM, Laux G, Bachl J, et al. Stringent doxycycline-dependent control of gene 
activities using an episomal one-vector system. Nucleic Acids Res. 2005;33:e137.

38. Scarfo I, Pellegrino E, Mereu E, Kwee I, Agnelli L, Bergaggio E, et al. Identification of a new subclass of ALK-negative ALCL expressing aberrant levels of ERBB4 transcripts. Blood. 2016;127:221-32.

39. Piccaluga PP, Agostinelli C, Califano A, Rossi M, Basso K, Zupo $\mathrm{S}$, et al. Gene expression analysis of peripheral $\mathrm{T}$ cell lymphoma, unspecified, reveals distinct profiles and new potential therapeutic targets. J Clin Invest. 2007;117:823-34.

40. Iqbal J, Weisenburger DD, Greiner TC, Vose JM, McKeithan T, Kucuk $\mathrm{C}$, et al. Molecular signatures to improve diagnosis in peripheral T-cell lymphoma and prognostication in angioimmunoblastic T-cell lymphoma. Blood. 2010;115:1026-36.

41. Malcolm TI, Villarese P, Fairbairn CJ, Lamant L, Trinquand A, Hook CE, et al. Anaplastic large cell lymphoma arises in thymocytes and requires transient TCR expression for thymic egress. Nat Commun. 2016;7:10087.

42. Bonzheim I, Geissinger E, Roth S, Zettl A, Marx A, Rosenwald A, et al. Anaplastic large cell lymphomas lack the expression of Tcell receptor molecules or molecules of proximal T-cell receptor signaling. Blood. 2004;104:3358-60.

43. Ivanov II, McKenzie BS, Zhou L, Tadokoro CE, Lepelley A, Lafaille J, et al. The orphan nuclear receptor RORgammat directs the differentiation program of proinflammatory IL-17+ $\mathrm{T}$ helper cells. Cell. 2006;126:1121-33.

44. Korn T, Bettelli E, Oukka M, Kuchroo VK. IL-17 and Th17 cells. Ann RevImmunol. 2009;27:485-517.

45. Glatzer T, Killig M, Meisig J, Ommert I, Luetke-Eversloh M, Babic M, et al. RORgammat $(+)$ innate lymphoid cells acquire a proinflammatory program upon engagement of the activating receptor NKp44. Immunity. 2013;38:1223-35.

46. He YW, Deftos ML, Ojala EW, Bevan MJ. RORgamma t, a novel isoform of an orphan receptor, negatively regulates Fas ligand expression and $\mathrm{IL}-2$ production in $\mathrm{T}$ cells. Immunity. 1998;9:797-806.

47. Kumar N, Lyda B, Chang MR, Lauer JL, Solt LA, Burris TP, et al. Identification of SR2211: a potent synthetic RORgammaselective modulator. ACS Chem Biol. 2012;7:672-7.

48. Xiao S, Yosef N, Yang J, Wang Y, Zhou L, Zhu C, et al. Smallmolecule RORgammat antagonists inhibit $\mathrm{T}$ helper 17 cell transcriptional network by divergent mechanisms. Immunity. 2014;40:477-89.

49. Hassler MR, Pulverer W, Lakshminarasimhan R, Redl E, Hacker $\mathrm{J}$, Garland GD, et al. Insights into the pathogenesis of anaplastic large-cell lymphoma through genome-wide DNA methylation profiling. Cell Rep. 2016;17:596-608.
50. Roukos V, Mathas S. The origins of ALK translocations. Front Biosci. 2015;7:260-8.

51. Shaulian E. AP-1--the Jun proteins: oncogenes or tumor suppressors in disguise? Cell Signal. 2010;22:894-9.

52. Werner SL, Barken D, Hoffmann A. Stimulus specificity of gene expression programs determined by temporal control of IKK activity. Science. 2005;309:1857-61.

53. Savan R, McFarland AP, Reynolds DA, Feigenbaum L, Ramakrishnan K, Karwan M, et al. A novel role for IL-22R1 as a driver of inflammation. Blood. 2011;117:575-84.

54. Matsuyama H, Suzuki HI, Nishimori H, Noguchi M, Yao T, Komatsu N, et al. miR-135b mediates NPM-ALK-driven oncogenicity and renders IL-17-producing immunophenotype to anaplastic large cell lymphoma. Blood. 2011;118:6881-92.

55. Montaldo E, Juelke K, Romagnani C. Group 3 innate lymphoid cells (ILC3s): origin, differentiation, and plasticity in humans and mice. Eur J Immunol. 2015;45:2171-82.

56. Simoni Y, Fehlings M, Kloverpris HN, McGovern N, Koo SL, Loh CY, et al. Human innate lymphoid cell subsets possess tissuetype based heterogeneity in phenotype and frequency. Immunity. 2017;46:148-61.

57. Bard JD, Gelebart P, Anand M, Amin HM, Lai R. Aberrant expression of IL-22 receptor 1 and autocrine IL-22 stimulation contribute to tumorigenicity in ALK+ anaplastic large cell lymphoma. Leukemia. 2008;22:1595-603.

58. Huh JR, Leung MW, Huang P, Ryan DA, Krout MR, Malapaka $\mathrm{RR}$, et al. Digoxin and its derivatives suppress TH17 cell differentiation by antagonizing RORgammat activity. Nature. 2011;472:486-90.

59. Isono $F$, Fujita-Sato $S$, Ito $S$. Inhibiting RORgammat/Th17 axis for autoimmune disorders. Drug Discov Today. 2014;19:1205-11.

60. Gordon KB, Blauvelt A, Papp KA, Langley RG, Luger T, Ohtsuki $\mathrm{M}$, et al. Phase 3 trials of ixekizumab in moderate-to-severe plaque psoriasis. N Engl J Med. 2016;375:345-56.

61. Gege C. RORgammat inhibitors as potential back-ups for the phase II candidate VTP-43742 from Vitae Pharmaceuticals: patent evaluation of WO2016061160 and US20160122345. Expert Opin Ther Pat. 2017;27:1-8.

62. Gambacorti Passerini C, Farina F, Stasia A, Redaelli S, Ceccon M, Mologni L, et al. Crizotinib in advanced, chemoresistant anaplastic lymphoma kinase-positive lymphoma patients. J Natl Cancer Inst. 2014;106:djt378.

63. Gambacorti Passerini C, Mussolin L, Brugieres L. Abrupt relapse of ALK-positive lymphoma after discontinuation of crizotinib. N Engl J Med. 2016;374:95-96.

\section{Affiliations}

\section{Nikolai Schleussner ${ }^{1,2} \cdot$ Olaf Merkel ${ }^{3,4} \cdot$ Mariantonia Costanza $\mathbb{1}^{1,2,4} \cdot$ Huan-Chang Liang ${ }^{3,4} \cdot$ Franziska Hummel ${ }^{1,2}$. Chiara Romagnani ${ }^{5,6} \cdot$ Pawel Durek $^{5}$ - loannis Anagnostopoulos ${ }^{7} \cdot$ Michael Hummel $^{7,8} \cdot$ Korinna Jöhrens $^{7}$. Antonia Niedobitek $^{1,2}$. Patrick R. Griffin ${ }^{9}$. Roberto Piva ${ }^{10}$. Henrike L. Sczakiel ${ }^{1,2}$ - Wilhelm Woessmann ${ }^{4,11}$. Christine Damm-Welk ${ }^{4,11} \cdot$ Christian Hinze $^{1,12} \cdot$ Dagmar Stoiber $^{13,14} \cdot$ Bernd Gillissen $^{2} \cdot$ Suzanne D. Turner ${ }^{4,15}$. Eva Kaergel ${ }^{1} \cdot$ Linda von Hoff $^{1} \cdot$ Michael Grau $^{16,17} \cdot$ Georg Lenz $^{16,17} \cdot$ Bernd Dörken $^{1,2,8} \cdot$ Claus Scheidereit $^{1}$. Lukas Kenner ${ }^{3,4,14,18,19} \cdot$ Martin Janz ${ }^{1,2,20} \cdot$ Stephan Mathas ${ }^{1,2,4,8,20}$}

1 Max-Delbrück-Center for Molecular Medicine, 13125 Berlin, Germany

2 Hematology, Oncology, and Tumor Immunology, CharitéUniversitätsmedizin Berlin, 12200 Berlin, Germany
3 Institute of Clinical Pathology, Medical University of Vienna, Vienna, Austria

4 European Research Initiative on ALK-Related Malignancies (ERIA), Cambridge, UK 
5 German Rheumatism Research Centre, German Rheumatism Research Centre (DRFZ), A Leibniz Institute, 10117 Berlin, Germany

6 Medical Department I, Charité-Universitätsmedizin Berlin, 12200 Berlin, Germany

7 Institute of Pathology, Charité-Universitätsmedizin Berlin, 10117 Berlin, Germany

8 German Cancer Consortium (DKTK), German Cancer Research Center (DKFZ), 69120 Heidelberg, Germany

9 The Scripps Research Institute, Jupiter, FL 33458, USA

10 Department of Molecular Biotechnology and Health Sciences, Center for Experimental Research and Medical Studies, University of Torino, Torino, Italy

11 NHL-BFM Study Centre and Department of Paediatric Haematology and Oncology, Justus-Liebig-University, Giessen, Germany

12 Department of Nephrology, Charité-Universitätsmedizin Berlin, 12200 Berlin, Germany
13 Institute of Pharmacology, Center for Physiology and Pharmacology, Medical University Vienna, Vienna, Austria

14 Ludwig Boltzmann Institute for Cancer Research (LBI-CR), Vienna, Austria

15 Department of Pathology, University of Cambridge, Cambridge CB21QP, UK

16 Department of Medicine A, Albert-Schweitzer-Campus 1, University Hospital Münster, 48149 Münster, Germany

17 Cluster of Excellence EXC 1003, Cells in Motion, 48149 Münster, Germany

18 University of Veterinary Medicine, Vienna, Austria

19 CBmed, Center for Biomarker Research in Medicine, 8010 Graz, Austria

20 Experimental and Clinical Research Center, a joint cooperation of Max-Delbrück-Center for Molecular Medicine and Charité Universitätsmedizin Berlin, 13125 Berlin, Germany 